\title{
How to Teach Aural English More Effectively
}

\author{
Huan Huang \\ English Department, Luohe Medical College \\ No.148 DaXue Road, Luohe 462002, China \\ E-mail:hh860109@yahoo.com.cn
}

\begin{abstract}
As a means of communication, listening plays an important role in people's life. In foreign language classroom, listening comprehension has never drawn the same attention of educators as it now does. So it is a vital importance to teach aural English more effectively. In view of present situation of aural English teaching and wrong ideas about it, the problems in traditional aural English teaching have been discussed, including monotonous pattern of teaching, ineffectiveness of teachers' roles, students' passivity, orientation at exams instead of students' abilities and so forth. Then suggestions are presented on how to teach aural English more effectively: first, diversifying patterns of teaching should throw the emphasis on teaching in authentic environments and interaction between listening and other teaching activities; secondly, teachers should design listening activities for the class, build good interaction in the class and cultivate more creative methods in their teaching to change their ineffective roles; thirdly, students' passive roles in class should also be modified by harmonizing their extrinsic motivations and intrinsic motivations; finally, the relationship between exams and development of abilities should be coordinated by using different strategies in different cases. Yet, there still exist a lot of problems in aural English teaching. For example, how to use authentic recordings in aural English teaching? Is it necessary to have audio equipment in order to train listening skills? And how to build the listeners' confidence in listeners? etc. Therefore, there is still a long way to go for EFL educators.
\end{abstract}

Keywords: Aural English, Problems, Suggestions

\section{Introduction}

\subsection{The present situation of aural English teaching}

The ability to understand and participate in speech communication is one of recent concerns in foreign language education that has generated a stronger focus on listening in the classroom. It is one of the main tasks of teachers to teach aural English more effectively so as to improve students' aural ability. Not only should teachers know the teaching materials well, but also they should pay more attention to teaching methods. However, the present situation of aural English teaching is not satisfactory. Though there is at least one hour of listening for every college student every week, the students who share the same textbooks and tape-recorders are not interested in their aural English classes and they are bored with monotonous class atmosphere in which they usually listen to some materials and finish their exercises and then check their answers with teachers. The teachers are also bored with pressing the play button and repeating the answers again and again. All the participants in aural classes are tired of having this kind of courses. All above-mentioned are caused by the wrong ideas about aural English teaching.

\subsection{Wrong ideas about aural English teaching}

First, it is thought that teaching aural English is easier than other courses. Instead of good preparation before classes and considerate arrangement inside classes, aural English teachers are used to playing the tapes for students in their classes. Second, choice of listening materials is not considerate as important in teaching. According to a research, listening materials have not been changed for several years. As is known to all, one of the main reasons for getting students to listen to spoken English is to let them hear different varieties and accents rather than just the voice of their teachers and tape-recorders with their own idiosyncrasies. Therefore, listening materials play an important role in teaching. Third, it is wrongly considerate that the same listening tasks are applicable for all students of different levels. Teachers usually let students listen to the same materials and do the same exercises in teaching instead of considering students' different levels. Furthermore, it is believed that getting the answers to questions is the purpose of aural English teaching. As a result, so many misunderstandings cause a lot of problems in our teaching. Therefore, it is important for educators to think over how to teach aural English more effectively.

\section{Problems in Traditional Aural English Teaching}

\subsection{Monotonous pattern of teaching}

Most people think that teaching aural English is easier than teaching other aspects of language, because the purpose of aural English is clear and teaching pattern is unchangeable. At present, teaching aural English is beyond realistic environment. First, students cannot see speakers, and have no chance of responding to speakers. They can just imagine 
the situation in their mind. Then, the tape-recorders' speeches are quite different from those in real life: they are more formal and unnatural. These problems make it hard for students to adapt themselves to an authentic environment of communication.

Apart from that, listening is not an isolated activity in class. However, we seldom see students read, speak and write something in aural class. As an old saying shows: One tree doesn't make a forest. All the learning activities are combined together. Monotonous pattern of teaching obviously result in both teachers' unconcern and students' indifference.

\subsection{Ineffectiveness of teachers' roles}

Most of aural English teachers do not have a teaching plan. They usually ask students to listen and then finish the exercises based on the sequence of textbook. In this case, teachers are equal to an intelligent machine. As we know, telling people how to master the skills of fishing is much more important than giving them fish. Therefore, telling students the listening methods is better than giving their answers. Ineffectiveness of teachers' roles causes the effect that students have learned little from them. In addition, teachers always keep silent except in the circumstances of checking answers with students. Depressing atmosphere makes students feel oppressive, and little communication brings us an unsatisfied result.

\subsection{Students' passivity}

First, students do not need to think about the answers to the exercises that are available in the listening materials. Their motivation for taking part in aural English class is that they want to get high mark in exams instead of developing themselves. Secondly, students always do something under the teachers' instructions. Teachers control the process of class. Thirdly, the only way for students to participate in aural English class is to listen. Therefore, they are passive in class. Students' passivity makes teachers also inactive, so we must try our best to break the vicious circle.

\subsection{Orientation at exams rather than students' abilities}

So many teachers and students pay much attention to exams, and the purpose of daily teaching is to make students achieve their goals in exams, therefore, finishing the exercises on the textbook is the main project in aural English class. It may results in slow improvement in students' abilities. For example, it takes nearly a whole term for teachers to give students specific training before TEM-4 or TEM-8, but the results of these exams are not always as good as expectation. In fact, our purpose of learning aural English is to communicate with foreigners easier and understand their culture, while examination is a means to achieve that goal. At present, the real purpose is covered by its means. That phenomenon sets us off thinking.

\section{Suggestions for aural English teaching}

\subsection{Diversifying patterns of teaching}

\subsubsection{Creating authentic environments of learning}

At present, monotony of teaching patterns is a largest problem in aural English teaching. It seems as if aural English teaching is conducted on a fixed model, in which students listen to the tape and check the answers with teachers. They sit usually in the same classroom and do the same things. In fact, listening environments and materials affect our degree of understanding. The purpose of aural English teaching is to cultivate students' abilities of understanding authentic materials. To reach this purpose, teachers should try to create authentic environments of learning, which has the following features:

1) Visibility of the speakers

In most situations, listening is not just an aural activity. We are usually able to see speaker, who provides non-verbal clues to meaning, for example, lip movements, facial expression, and gestures. (Hedge, 2002: 242) So we should think again about how much we ought to use recordings as the basis of our exercises in aural English class and teachers are encouraged to make full use of conversation on videos or communicate with students by words.

\section{2) Participation of the listeners}

In many, perhaps most, cases the listener is required to give some kind of overt, immediate response to what has been said. This may be verbal (the answer to a question, for instance) or non-verbal (action in accordance with instructions, a nod of the head, for example). Even a lecturer or orator gets some sort of feedback from his audience in the form of facial expression.

Yet many classroom listening comprehension exercises demand no response until the end of fairly long stretches of speech, so that when it comes this response is very largely a test of memory rather of comprehension. The teachers should try their best to have the students take the initiative in learning in class. The students should take part in listening materials under the personal direction of their teacher. 


\section{3) Environmental features}

Apart from the speaker himself-his facial expression, posture, eye direction, proximity, gesture, tone of voice-a real-life listening situation is normally rich in environmental clues as to the content and implications of what is said. Often noises or smells or other sense-stimulus can contribute valuable background information, but I think it is true to say that most environmental clues are visual. Occasionally the general surroundings contribute information. If we are in a railway station, for example, and hear an announcement over the loudspeaker, we expect it to announce the arrival or departure of a train.

"Environmental clues are often more likely to provide information about the situation, speakers and general atmosphere than about the actual topic of discourse."(Ur, 2000: 5) If the listener/onlooker cannot understand the meaning of the words used in a family discussion, board meeting or political harangue, he will not be able to say much about the subject of debate, what he will be able to guess fairly accurately, however, are things such as the level of formality, the amount and kind of emotional involvement of the speakers, the kind of relationship existing between speakers and listeners-all of which afford him significant assistance in comprehending the sense of what is said once he actually understands at least some of the language. Sound recording, broadcasts and telephone conversations used in aural English class are relatively poor in such clues, but these normally comprise only a small part of our total listening activity. In classroom terms, environmental clues are normally represented by visual materials (illustrations, diagrams, maps and so on) which are thus essential to the effective presentation of most listening exercises and which should be used widely.

\section{4) Real-life language features}

It is necessary to draw a distinction between formal speech or 'spoken prose' and the informal speech used in most spontaneous conversation. Informal speech is usually both spontaneous and colloquial; formal speech is usually characteristically neither.

It would seem reasonable to say that classroom practice should usually incorporate such characteristics of real-life listening, as those described above; yet many books of listening exercises do not include any of them at all. Such books are made up of passages originally composed as written texts (extracts from novels, newspaper articles and so on) recorded onto tape, the listeners listen to the text without knowing much about what they are going to hear or what they are listening for, and then have to answer comprehension questions, usually multiple choices. This is a convenient classroom technique, and it does give a certain type of practice, but it does not provide any realistic preparation for real-life listening. A learner who relies on this type of exercise is going to have a awakening when he tries to understand native speech in natural communicative situation. Therefore the selection of listening materials is very important in teaching. The materials should be authentic instead of imaginative.

\subsubsection{Integrating listening with other teaching activities}

"For almost six decades now research and practice in English, language teaching has identified the 'four skills'-listening, speaking, reading and writing-as of paramount importance". (Brown, 2000: 218) With all our history of treating the four skills in separate segments of a curriculum, there is nevertheless a more recent trend toward skill integration, which makes aural English teaching more varied.

1) Oral activities in aural teaching

Students with accurate aural perception can often reproduce sounds they hear without having the slightest idea of what these mean. However, the more complex the material is reproduced, the more difficult it is to repeat it accurately without understanding. Repetition is based on understanding. On the other hand, repetition is rather time-consuming. One student repeats a single word or a sentence, while most students are silent and relatively inactive most of time. So some useful practice may be obtained by the use of pair-work or group-work (students take turns to repeat it). In addition, when students' listening is improved through repetition to some extent, a role-playing and imitation are appropriate to them. It is a process that remembering is changed into understanding. All the oral activities diversify the patterns of class and improve students' aural abilities.

2) Reading and writing activities in aural teaching

Students always listen to materials and teachers' words in aural class. In fact, reading and writing activities help students understand to a certain extent. After listening, reading the materials under teachers' instruction assist them to have a full understanding of background knowledge and contents of the materials. Besides, asking one student to read a passage he prepared before class is also a good opportunity for others to practice their listening, which at the same time makes students be accustomed to varied accent. Furthermore, accuracy of pronunciation through reading is improved. Then, doing blank filling and writing down their opinion about listening materials will help students understand them correctly and fully.

To sum up, there are a lot of methods to diversify patterns of aural teaching. Teachers may choose one of them or some 
of them to achieve their teaching goals depending upon different circumstances.

\subsection{Modifying teachers' roles}

\subsubsection{Designing Listening Activities for the Classroom}

Listening is one of the most challenging skills for our students to develop and yet also one of the most important. By developing their ability to listen well we develop our students' ability to become more independent learners, as by hearing accurately they are much more likely to be able to reproduce accurately, refine their understanding of grammar and develop their own vocabulary. This section is to outline a framework that can be used to design a listening lesson that will develop your students' listening skills and look at some of the issues involved.

\section{Pre-listening}

There are certain goals that should be achieved before students attempt to listen to any text. First, it is enormously important that before listening students are motivated to listen, so the teacher should try to select a text that they will find interesting and then design tasks that will arouse your students' interest and curiosity. Besides, "the teachers can also emphasize learning processes by stating goal before listening. Such statements are important because learners are made aware of what the teachers are trying to achieve." (Nunan, 2001: 218) Secondly, listening to a tape recording in a classroom is very unnatural process. The text has been taken from its original environment and teachers need to design tasks that will help students to understand the text. Teachers should provide background knowledge and specific vocabulary or expressions for students before listening. It's vital that teachers cover this before they start to listen.

\section{While-listening}

"The work at the while-listening stage needs to link in relevant ways to the pre-listening work. While they listen, learners will need to be involved in an authentic purpose for listening and encouraged to attend to the text more intensively or more extensively, for gist or for specific information.”(Hedge, 2002: 252) For learners in the early stages of developing listening ability, simple activities such as ticking a list or numbering pictures in correct order will prevent the anxiety arising from trying to write while listening. More advanced learners will be able to cope with more complex tasks. There are sometimes three times for listening. The first listening task makes students grasp a general understanding of the text, then students should have a greater and more detailed understanding of the text in the second time; The third listening task could just be a matter of checking their own answers from the second task or could lead students towards some more subtle interpretations of the text.

\section{Post-listening}

In this session, the teachers and students check and discuss the response to the while-listening task. The teachers' role is to help students see how successful they have been in doing the task. Furthermore, post-listening work can also usually involve integration with other skills through development of the topic into reading, speaking, or writing. If materials follow this route, it becomes important to ensure that new sources of motivation arise for students other than the interest of the original text.

Within this section I have tried to describe a framework for listening development that could be applied to any listening text. This isn't the only way to develop our students listening or to structure a listening lesson, but it is one of effective and motivating ways for students.

\subsubsection{Building Good Interaction in Classroom}

In aural English classrooms, the language, whether it is English or native language is the medium through which teachers teach, and students demonstrate what they have learned.

\section{1) Teacher-student interaction}

"Most of the teacher-student interaction in a lesson follows the pattern that beginning with teacher initiation, which is followed by a student's response, and then the teacher's evaluation of that response."(Johnson, 2000: 96) In aural English class, teacher's evaluations depend on the students' responses to both the teacher's initiation and materials they listen. Consequently, listening is the medium for an exchange between teachers and students. In aural teaching, teachers are encouraged to give students initiation to arouse their interest instead of keeping silent. "Apart from adapting their language, experienced teachers also use physical movements: gestures, expressions, and mime. It becomes almost second nature to show happiness and sadness, movement and time sequences, concepts using these techniques. They become a part of the language teachers' use, especially with students at lower levels". (Scrivener, 2002: 98)

Meanwhile, teachers should encourage students to communicate with them. For example, asking students to speak out their answers to listening exercises is one of the effective ways. In addition, listening exercises is not only a process that students understand and remember something, but also a preparation for thinking. Then they may discuss their thoughts with students by asking questions. In a word, interaction between teachers and students will forward the development of their listening. 


\section{2) Student-student interaction}

So far, much of our attention has focused on understanding classroom communication by looking at the interaction that occurs between teachers and students. However, by doing so we have ignored another important dimension of classroom interaction occurs between students themselves. In aural English class, interaction between students seldom occurs. In fact, this interaction, such as pair work, group work, is good for lessons, makes contribution to their understanding. Meanwhile, the exchange of ideas by English is another chance for them to listen something about materials. On the other hand, teachers must also effectively harmonize the conflicts inevitable in student-student interaction.

\subsubsection{Employing Creative Methods of Teaching}

It is important to develop students' creativity and practice in education reformation at present, while classroom teaching is the main position to achieve it. Teachers' primary task is to change traditional conception of education and train qualified talent. Then what are teachers' creative methods in aural English class?

1) Arousing questions in students' mind

"According to a certain teaching content and listening materials, it is necessary for teachers to design a lot of flexible questions before class". (McDonough, 2000:171). Maybe there are various answers to these questions. Although they have listened to the same materials, they may give different answers based on the degrees of their understanding. In addition, teachers may stop listening to ask students what will happen next while listening. Students may give different answers. "Another way of increasing learner involvement is by providing extension tasks that take the listening materials as a point of departure, but which then lead learners into providing part of the content themselves". For example, the students might listen to someone describing the work they do, and then create a set of questions for interviewing the person. Therefore, the task of aural English is that students' listening abilities would be improved instead of just getting the answers to exercises in their students' books.

\section{2) Making students participate actively in class}

In traditional aural English class, teachers ask students to do something according to their teaching plan. Nowadays, the relationship of equality and cooperation between teachers and students is encouraged because free class is beneficial for students to study well. In aural English class, teachers should encourage students to take part in class actively. For example, a role-playing based on listening materials and listening to something popular and interesting will bring us unimaginable effects.

\subsection{Modifying students' roles}

As mentioned above, students now play passive roles in class. It's important to modify students' roles in aural English class. Let's see something useful: "One of the most successful language learning experiences we know about took place towards the end of the Second World War when the American military needed to train their personnel the languages of the countries they would have to administer and/or deal with. In short intensive courses, the students learnt fantastically fast."(Harmer, 2000: 8) In fact, a lot of factors affect listening; however, learner's motivation is obvious among them.

\begin{tabular}{lc} 
Factors of Listeners & Concerned with Results in Listening \\
\cline { 2 - 2 } Motivation & 0.727 \\
Tactics & 0.715 \\
Language knowledge & 0.676 \\
Background knowledge & 0.623 \\
Mentality & 0.565 \\
Learners' background & 0.432
\end{tabular}

(DengYuan, Yang Zhiqing 2004:11)

Therefore, motivation is the most important factor. Researchers divide learners' motivation into two kinds: extrinsic motivation and intrinsic motivation. "Extrinsic motivation comes from the desire to get a reward or avoid punishment; the focus is on something external to learn activity itself. With intrinsic motivation the learning experience is its own reward. Research indicates that, while extrinsic motivation can also be beneficial, learning is most favorably influenced by intrinsic orientations, especially for long-term retention."(Arnold, 2000: 14) So it is important to develop intrinsic motivation in order to change their passive role. It is much more interesting to respond actively to something than to listen passively, and a well-constructed task can be fun as well as beneficial to listening, for an element of puzzle-solving or game-playing is easily built in. Here we must try to avoid boring or over-theoretical subjects, using the ones we think our students may interest in, that seem to be of practical relevance, and may arouse or stimulate their interests. A little drama or humor can do a great deal towards such purpose if it is not of a particularly high standard of 
sophistication. Connection between intrinsic motivation and external motivation may change students' passive roles and make them active in class.

\subsection{Coordinating the relationship between exams and development of abilities}

\subsubsection{Their correlation}

This issue of correlation between exams and development of abilities becomes crucial when teachers are giving their students instructions. What is the correlation between them? There is a continuing debate about that. An exam whose purpose is to improve students' abilities rather than discriminate among students is one of the tools for testing students' abilities. Meanwhile, the result of exams will stimulate students to study well. In aural English class, exams such as filling the blanks, making choices in daily exercises and even formal exam papers are everywhere. Those exams indeed make students pay much attention to their scores of exams. However, overemphasis on exams brings students pressure. On the other hand, development of students' abilities can be reflected in their exams. A competent student can do well in exams; therefore, exams and development of their abilities are not contradictory. However, why are the relationships between them dealt with badly sometimes?

\subsubsection{Strategies}

First, appropriate training before exams is beneficial to the improvement of students' abilities, which can familiarize the students with the task types in exams.

Another way in which students' ability has been improved is that aural English teachers tell them some listening skills instead of how to finish exam paper. Having mastery of listening skills enable students to cope with all kinds of examination with ease, while training in light of a certain examination do not benefit them a lot.

In addition, teachers should make the teaching plans on the premise of combination of training for exams and development of ability. Teachers coordinate the relationship between them in their daily teaching. For example, content of exam is infiltrated into cultivation of ability, while there is focalization in it.

\section{Conclusion}

Obviously, we have faced many problems in aural English teaching. Anyhow, we must try our best to solve them. Aural English teaching involves the teaching patterns, teachers' and students' roles in class and the correlation between exams and development of abilities. Various patterns of teaching might attract both teachers and students. Besides, teachers should provide as much positive practice as possible by talking to learners in English, by exposing them to a range of listening materials in the classroom, and by encouraging them to use whatever resources available in their institution or community in the ways suggested in this paper. Meanwhile, ways should be cultivated to involve more actively in class. Furthermore, teachers should coordinate the relationship between exams and development of abilities. To sum up, it is important to pay more attention to aural English teaching, and we still have a long way to go.

\section{References}

Arnold, Jane. (2000). Affect in Language Learning. Cambridge: Cambridge University Press.

Brown, T. H. Douglas. (2000). Teaching by Principles: An Interactive Approach to Language Pedagogy. Beijing: Foreign Language Teaching and Research Press.

Deng Yuan \& Yang Zhiqing. (2004). The role of learner factors in listening comprehension. Educational Technology for Foreign Language Teaching (1).

Harmer, Jeremy. (2000). How to Teach English. Beijing: Foreign Language Teaching and Research Press.

Hedge, Tricia. (2002).Teaching and Learning in Language Classroom.Shanghai: Shanghai Foreign Language Education Press.

Johnson, Karen E. (2000).Understanding Communication in Second Language Classrooms. Cambridge: Cambridge University Press.

McDonough, Jo \& McDonough, Steven. (2000). Research Methods for English Language Teachers. Beijing: Foreign Language Teaching and Research Press.

Nunan, David. (2001). Second Language Teaching and Learning. Foreign Language Teaching and Research Press.

Scrivener, Jim. (2002). Learning Teaching: A Guide Book for English Language Teachers Shanghai: Shanghai Foreign Language Education Press.

Ur, Penny. (2000).Teaching Listening Comprehension. Beijing: Foreign Language Teaching and Research Press. 